\title{
Building commitment: An examination of learning climate congruence and the affective commitment of academics in an Australian university
}

\begin{abstract}
The purpose of this study is to explore the relationship between learning climate congruence and the affective commitment of university academics. The strategy of inquiry for this research is quantitative, involving a non-experimental design for the survey research. A nonprobability sample of 900 academics from a large Australian university was selected with a response rate of $30.33 \%$. The major conclusion drawn from this study was that the congruence between current and preferred learning climate was related to the affective commitment of university academics. More specifically, academic's level of affective commitment was enhanced in a learning climate where they were encouraged to take risks, had plenty of time to learn new tasks, and were encouraged to openly express their ideas and opinions. This study is important in a practical sense to academic managers and universities to build relationships and develop better connections with their academics.
\end{abstract}

Keywords: Person-organisation congruence, learning climate, affective commitment, university academics

Article Classification: Research paper 


\section{Introduction}

The purpose of this study is to understand how academics' commitment impacts on their professional development and retention, through investigating how the congruence between current and preferred learning climate influences the affective commitment of academics. There are a number of challenges with managing academics, including high costs associated with replacing human resources (Alvesson 2004; Janz and Prasamphanich 2003; Mitchell, Holtom and Lee 2001; Shah, Lewis and Fitzgerald 2011; van Balan, van Arensbergen, van der Weijden and van den Besselaar 2012), increases in employee transience and shortages of qualified knowledge employees (Janz and Prasamphanich 2003). While the ability to attract, retain and develop competent employees is important for all organisations, Alvesson (2004) contends that the issue is amplified for academics not only because of their access to educational opportunities, but also because academics own the means of production: their knowledge (Kinnear and Sutherland 2000).

Academics also tend to be more committed to their occupation or profession, rather than the organisation (Alvesson 2000; Benson and Brown 2007; Cook 1996; Horwitz, Heng and Quazi 2003; Joo 2010; May, Korczynski and Frenkel 2002; O'Neill and Adya 2007; Roberston and Hammersley 2000; Thite 2004; van Balan et al. 2012). Deem (2009) found that academics' commitment tends to be oriented towards the basic academic unit and subject or discipline, not the interests of the university as a whole. Benson and Brown (2007) contend that the complexity and ambiguity of academic work, coupled with the strong professional orientation, tend to promote less identification with the organisation and higher levels of intention to quit. As a result, the authors stress the importance of finding ways to enhance the connection and commitment of academics and their universities.

Difficulties are further enhanced in the development and retention of academics due to the nature of academic work, where academics do not have enough time to learn new tasks 
and, due to the increasing amount of administrative responsibilities (Siegall and McDonald 2004; Winter and Sarros 2002). Also, the bureaucratic nature of universities (Jones 2007) inhibits the ability to adapt learning and development needs to each academic.

This article will outline the literature relating to person-organisation congruence and the importance of learning climate and affective commitment in congruence research, which form the hypotheses for this study. Methodological procedures, results and discussions will be outlined and limitations and implications discussed.

\section{Australian Higher Education sector}

The Higher Education sector in Australia is made up of 39 universities (37 public and 2 private) and approximately 150 other higher education institutions, often referred to as higher education providers (Bandias, Fuller and Pfitzner 2011). The Higher Education sector has changed dramatically over the last 30 years. What once consisted of small publiclyfunded institutions now consists of public universities deriving significant proportions of their income from non-government sources and some private providers receiving government subsidies (Bradley, Noonan, Nugent and Scales 2008). A renewed interest in the quality of assurance in Australian Higher Education and the implementation of the quality assurance framework in 2000 has sparked various changes in this sector. Changes include the growth and diversity of the student population, the growth of private sector higher education providers, increase in technology in learning and a decline in public funding for university (Shah et al. 2011). Higher demands for quality are also putting pressure on the capacity of the higher education sector in Australia to meet future labour market needs. The ageing academic workforce (also a global issue), the dependence on casual workers, the difficulty in attracting and retaining high-quality academic staff and the global demand for quality academics (Bradley et al. 2008) have resulted in a skill shortage in Australia. 


\section{Person-organisation congruence}

Person-organisation congruence is the compatibility that occurs when people and organisations share similar characteristics (Kristof 1996) and is based on the assumption that each individual seeks to achieve, maintain and optimise their association with a specific environmental component, such as their organisation (Dawis and Lofquist 1984). This has been an appealing concept for managers due to the positive psychosomatic consequences (job satisfaction, organisational commitment, identification, and retention) that can accrue when individuals perceive a good congruence between themselves and their environment (Andrews, Baker and Hunt 2011; Erdogan and Bauer 2005; Hoffman and Woehr 2006; Kim 2012; Kristof-Brown, Zimmerman and Johnson 2005; Mitchell, Parker, Giles, Joyce and Chiang 2012; Morely 2007; VanVianen 2000; Verquer, Beehr and Wagner 2003; Westerman and Cyr 2004; Wheeler, Gallagher, Brouer and Sablynskil 2007). Such positive consequences are key issues for organisations where competitive advantage lies in the knowledge and skills of their employees (Alvesson 2004).

Kristof (1996), Piasentin and Chapman (2006), Kristof-Brown, Zimmerman and Johnson (2005), and Morley (2007) define four ways to conceptualise this theory, namely, supplementary congruence, complementary congruence, needs-supplies and demandsabilities perspectives. Supplementary congruence refers to how an organisation and an individual share similar characteristics, such as values and culture (Carless 2005; Kristof 1996). Complementary congruence is how an organisation and an individual contribute to the fulfilment of each other's needs (Kristof 1996) and is often used with congruence to the job, rather than to the organisation (Piasentin and Chapman 2006).

The needs-supplies perspective is when an organisation satisfies the needs, desires and/or preferences of an individual (Kristof 1996; Morely 2007; Piasentin and Chapman 
2006) and assumes that congruence between the individual and the organisation leads to satisfaction and various positive individual outcomes (Kristof-Brown et al. 2005; Kristof 1996). This perspective is primarily concerned with meeting employee needs (Cable and DeRue 2002). In contrast, the demands-abilities perspective suggests that congruence occurs when an individual has the abilities or skills required to meet the demands of the job or the organisation (Chan 1996; Kristof 1996; Verquer et al. 2003). According to Kristof-Brown, Zimmerman and Johnson (2005) this perspective has the least amount of influence on employee attitudes, as it emphasises meeting environmental needs, rather than individual needs.

The current study involves a combination of the supplementary and needs-supplies perspectives. The supplementary perspective looks at the similarities between individual and organisational characteristics, while the needs-supplies perspective contends that the compatibility between individuals' needs or preferences, and the organisation's structure or systems, will result in positive employee attitudes.

Many researchers have operationalised person-organisation congruence through the use of various content dimensions. Organisational characteristics include climate, culture, values, goals and norms, while individual characteristics include personality, values, goals, preferences and attitudes (Bretz and Judge 1994; Kim 2012; Kristof-Brown et al. 2005; Lauver and Kristof-Brown 2001; Morely 2007; O'Reilly, Chatman and Caldwell 1991; Piasentin and Chapman 2006). This study aims to enhance the person-organisation congruence literature, through using learning climate to operationalise the theory. This study is unique in the context (university academics) and outcome variable (affective commitment) used in relation to learning climate congruence research. 


\section{Learning Climate and Person-organisation congruence}

Learning climate was selected in this study as a way to examine the learning environment in a higher education setting. Academics perceive learning practices, procedures and rewards for learning in particular ways, and cluster their experiences which form the basis of the organisation's learning climate (Ortenblad 2002). The controversy about what a learning climate is increases the complexity of how learning climate is used in this study. Culture and climate are sometimes seen as distinct organisational variables, sometimes arising from different academic traditions, and as rival theoretical concepts. However, culture and climate are also viewed as reflecting similar manifestations (Braithwaite, Greenfield and Westbrook 2008; Mohamad Najib Abdul Ghafar 1999). The concept of the learning organisation revolves around organisational culture and climate characteristics that help develop a learning culture (Dymock and McCarthy 2006; Graham and Nafukho 2007). However, there is no widely accepted theory of what comprises the culture and climate of a learning organisation (Cunningham and Iles 2002). Senge (1990), and Pedler, Burgoyne and Boydell (1991) are among the few researchers who have attempted to delineate the culture and climate characteristics of the learning organisation. Pedler, Burgoyne and Boydell (1991) define the learning organisation as an organisation that facilitates the learning of all of its members and continuously transforms itself in order to meet its strategic goals. Both models focus on certain input elements that are necessary in the knowledge creation process and are the bases for radical new outputs (Lee-Kelley, Blackman and Hurst 2007).

Pedler, Burgoyne and Boydell (1991) argue that a positive learning climate is one in which individual members are encouraged to learn and to develop their full potential; one that extends the learning culture to include customers, suppliers and other significant stakeholders; that makes human resource development strategy central to business policy and, that continually undergoes a process of organisational transformation. This study is consistent 
with Pedler, Burgoyne and Boydell's (1991) framework as it is one of the more coherent and practically oriented learning theories (Thomsen and Hoest 2001).

The organisational characteristics most commonly used in the research on individualorganisation congruence include characteristics such as culture, climate, values, goals and norms (Kristof-Brown et al. 2005; Kristof 1996). The current study utilised the learning climate as the organisational characteristic, which includes structural elements within the organisation that are used to facilitate learning (Ortenblad 2002). Few researchers have used learning climate in person-organisation congruence research. Mikkelsen, Ogaard and Lovrich's (2000) survey of 693 Norwegian health care employees, and Mikkelsen, Saksvik, and Ursin's (1998) survey of 383 Norwegian postal service employees, found that a positive learning climate reduces job stress and also has a direct and positive impact on job satisfaction and commitment. The authors also found that positive perceptions of the learning climate contribute to job satisfaction, affective commitment and intent to remain with the organisation.

\section{Affective commitment and Person-Organisation congruence}

Affective commitment refers to an individual's emotional attachment to, identification with, and involvement in an organisation (Meyer and Allen 1991; Meyer, Stanley, Herscovitch and Topolnytsky 2002). Affective commitment is based on the attitudinal perspective of commitment (Mowday, Porter and Steers 1982) which focuses on the process by which people come to think about their relationship with the organisation and whereby individuals consider the extent to which their own values are congruent with their organisation.

Meyer and Herscovitch (2001) state that shared values are a fundamental basis for affective commitment. Empirical studies confirm the link between person-organisation 
congruence and organisational commitment (Cable and DeRue 2002; Tepeci 2001; Van Vuuren, De Jong and Seydel 2007; VanVianen 2000; Verquer et al. 2003; Wasti 2003). More specifically, research has also found that person-organisation congruence influences the level of affective commitment. Howell, Kirk-Brown and Cooper's (2012) survey of 343 employees in 5 private sector organisations and one government utility in Australia found that value congruence was positively related to affective commitment. Lawrence and Lawrence's (2009) survey of 361 business students at two Australian universities found that the congruence between individual and organisational values was positively related to affective commitment. In addition, VanVianen's (2000) survey of 154 employees from a variety of organisations in the Netherlands, and Cable and DeRue's (2002) survey of managers from a variety of industries (service, health care, high technology, education, food and beverage service, entertainment, consumer goods) in the US found that value congruence was significantly related to affective commitment. Thus, there is significant evidence in the literature to suggest that affective commitment is significantly and positively related to person-organisation congruence.

\section{Study Hypotheses}

Based on the previous theory and research this study hypothesizes that;

H1: Current Learning climate will be positively related to affective commitment

H2: Preferred learning climate will be positively related to affective commitment

H3: There will be a significant relationship between current and preferred learning climate

H4: The congruence between current and preferred learning climate will be positively related to affective commitment 
\{Figure 1. Hypothesized relationships between current and preferred learning climate and affective commitment here

\section{Method}

Design

The strategy of inquiry for this research is quantitative, and involves a nonexperimental design using a survey instrument. The data collection instrument is a crosssectional, self-administered questionnaire.

\section{Participants and Procedure}

A non-probability sample of 900 university academics from a total population of 1400 was selected from a large public tertiary institute in South East Queensland with five campuses (Gold Coast, Nathan, Mt Gravatt, Logan, South Bank) spanning across three cities from Brisbane to the Gold Coast. The university employs over 3500 staff, with approximately 1400 of these being academic staff. In addition, the university has more than 37000 students from more than 122 countries and is Australia's ninth largest higher education institution in terms of student load (Wong 2007). The university is comparable to most large universities and was selected due to its geographical spread of campuses. Ethical approval was provided by the authors' university ethics committee.

Data was collected via a paper-based questionnaire. Contact details (email and office locations) were gathered via the university website. Therefore, it was expected that the sample of academics used in this study were full-time and either on a fixed-term contract or a permanent tenure with the university. First, an advance notice email was sent out to participants one week prior to delivering the questionnaire to inform them about the research 
and that their responses would be anonymous. To maximise the research participation, an incentive was offered whereby all participants who returned a completed survey were entered into a prize draw with the chance of winning a $\$ 100$ store voucher. Second, the questionnaire, cover letter, prize information and a pre-addressed return envelope were mailed to each academic. Third, up to 2 or 3 reminder emails were sent. Although, various techniques were used to enhance the response rate of the questionnaire, the response was moderate $(30.33 \%)$. Cycote and Harrison (2006) revealed that the mean response rate for mail-out surveys was 34\%. This response may have been due to the way the questionnaire was administered (mail-out) (Neuman 2000) and also due to the increasing work-load of administrative duties in academia.

\section{Materials}

\section{Measures of person-organisation congruence}

There are various ways to analyse and measure person-organisation congruence. Decisions need to be made on whether direct (perceived) or indirect (actual) congruence is to be analysed and whether commensurate or non-commensurate measures are to be used. Direct (perceived) congruence asks individuals to report their perceptions of congruence. Indirect or actual congruence is assessed through comparisons of separately rated individual and organisational variables (Kristof 1996). Indirect (subjective) measures are collected from individual and organisation variables reported by the same individual, rather than measured by a third party (objective). According to Kristof-Brown, Zimmerman and Johnson (2005) indirect (subjective) measures allow for the greatest level of cognitive manipulation, and enables important individual differences to be captured. This study used indirect, subjective measures where the congruence between current and preferred learning climate is measured on separately rated individual and organisational variables by the same individual. 
Commensurate measures describe both the individual and the organisation characteristics on the same content dimensions, while non-commensurate measures use different content dimensions (Kristof 1996). This study used commensurate measures where current and preferred learning climate are measured along the same content dimensions.

\section{Learning Climate}

Few contemporary researchers have developed measurement instruments for diagnosing a learning climate. This study created a new learning climate measure based on Pedler, Burgoyne and Boydell's (1991) Learning Climate Questionnaire. The learning climate questionnaire assesses ten factors, using ten items, to determine whether an organisation facilitates the learning of its members. These include: physical environment, learning resources, encouragement to learn, communications, rewards, conformity, value placed on ideas, practical help available, warmth and support and standards. McDougall and Beattie (1998) used Pedler, Burgoyne and Boydell's (1991) Learning Climate Questionnaire in their survey of 140 managers to determine the prevalent learning climate in the organisation. However, no reliability and validity coefficients were reported, creating a potential limitation for the current study.

For this study, current learning climate was measured using a fourteen-item scale. Items were measured on a 5 -point likert scale $(1=$ strongly disagree to 5 - strongly agree $)$. Sample questions for the current learning climate questions included "In my organisation, people are generally expected to conform to rules, regulations and policies" and "In my organisation, there are generally regular social discussions and interaction amongst colleagues". The reliability coefficient for the current learning climate scale was 0.523 .

Preferred learning climate was also measured using a fourteen item scale on a 5-point Likert scale. Sample questions for the preferred learning climate questions included "I prefer 
an organisation where people are generally encouraged to take risks and experiment with new ways of doing things" and "I prefer an organisation where people generally focus on their job, not on other peoples' feelings and emotions". The reliability coefficient for the preferred learning climate scale was 0.447 .

The exploratory principle components analysis revealed four factors in both the current and preferred learning climate scales. These included, Learning Resources, Encouragement to Learning, Value of Ideas Support and Help Available.

\section{Affective Commitment}

Allen and Meyer's (1990) eight-item Affective Commitment Scale was used to measure affective commitment. Items were measured on a 5-point likert scale $(1=$ strongly disagree to 5 - strongly agree). Sample questions include "I would be happy to spend the rest of my career with this organisation" and "I would recommend this organisation to others to work in". Allen and Meyer reported a reliability coefficient of 0.87 for the scale. Its reliability has been well documented in the literature, including, 0.87 and 0.89 (supermarket employees in the United States) (Holtom, Tidd and Lee 2002), 0.83 (customer service employees in the United Kingdom) (McDonald and Makin 2000). Holtom et al. (2002) confirmed the validity of the scale, finding positive relationships between affective commitment and employee work preferences, while McDonald and Making (2000) found positive relationships between affective commitment and the psychological contract. Various reliability coefficients were documented; 0.84 (Turkish employees) (Wasti 2003), 0.82 (undergraduate business students) (Abbott, White and Charles 2005) and 0.79 (Australian firefighters) (Iverson and Buttigieg 1999). Wasti (2003), Abbott et al. (2005) and Iverson and Buttigieg (1999) confirmed this validity as affective commitment had a positive relationship with work-related outcomes, 
such as turnover, job satisfaction and absenteeism. The reliability coefficient for the affective commitment scale in the current study was 0.84 .

\section{Demographic attributes}

Participants were asked to select their academic discipline from a list, academic level (Professor, Associate Professor, Senior Lecturer, Lecturer, Associate Lecturer, other), type of employment (full-time, part-time, sessional, fractional, half-time, other), length of service (less than 1 year, 1-3 years, 4-6 years, more than 6 years), intention to stay with the university (yes, no, unsure), promotions (yes, no, not applicable), age (25 and under, 26-35, 36-45, 4655, 56 and over) and gender.

\section{Data Analysis}

A number of data analysis procedures were used in this study. First, the descriptive statistics, including means, standard deviations, frequencies and percentages, were used to develop profiles on the demographic attributes. Second, an exploratory principal components analysis was conducted on the learning climate questionnaire (current and preferred items), to explore factor structures that may emerge. Third, reliability coefficients were determined for each of the questionnaire constructs. Fourth, Pearson's product-moment correlation was used to assess the relationships between current and preferred learning climate congruence, demographic variables and affective commitment. Finally, hierarchical linear regressions and interactions in multiple linear regressions were used to assess the relationship between current and preferred learning climate congruence and affective commitment.

\section{Results}

Demographic attributes 
Two hundred and seventy three university academics returned a completed survey; $51.6 \%$ were female. Respondents' ages ranged between 46 and 55 years (38.6\%), 36 and 45 years (27.9\%), 56 and 65 years (20.6\%), 26 and 35 years (10.7) and over 66 years $(2.2 \%)$, and were predominantly Caucasian. Participants included lecturers (37.3\%), senior lecturers (26.2), professors (17.7\%), associate professors (10\%) and associate lecturers (5.9\%). Faculties included Health (20.1\%), Business and Commerce (17.6\%), Arts, Languages and Criminology (15.4\%), Education (11.7\%), Engineering and IT (7.3\%), Science (5.9\%), Environment and Planning (4.0\%), Law and Music (3.7\%, respectively) and Visual and Creative Arts (2.6\%).

Most respondents $(88.6 \%)$ worked full-time and had been working at the university for more than 6 years $(51.6 \%)$. Others indicated that they had worked at the university for between 1 to 3 years $(23.8 \%), 4$ to 6 years $(19.8 \%)$, or less than 1 year $(4.8 \%)$. Most respondents intended on staying with the university $(66.3 \%)$, some respondents were unsure (17.9\%), and a small portion did not intend on staying with the university (8.8\%). Further, $50.6 \%$ of respondents had received a promotion.

\section{\{Table 1. Descriptive statistics\}}

\section{Principal components analysis}

A principal components analysis was conducted on the fourteen items of the current and preferred learning climate. Items with correlations over .30 were considered to be appropriate for inclusion in the principal components analysis (Coakes and Steed 2001; Tabachnick and Fidell 2001).

The first current and preferred learning climate factor was named 'Encouragement to Learn' and included items that related to whether people were encouraged to take risks, have 
plenty of time to learn new tasks, and were encouraged to openly express their ideas and opinions. For the current learning climate, the four items explained $45.493 \%$ of the variation in the data with an Eigenvalue above 1 (1.820). For the preferred learning climate, the four items explained $43.781 \%$ of the variation in the data with an Eigenvalue above $1(1.751)$.

The second current and preferred learning climate factor was named 'Value of Ideas' and included items that related to whether people were expected to conform to rules and regulations, people have the freedom make their own decisions, and the discussions of critical work issues were encouraged and valued. For the current learning climate, the three items explained $52.321 \%$ of the variation in the data with an Eigenvalue above 1 (1.570). For the preferred learning climate, the three items explained $48.443 \%$ of the variation in the data with an Eigenvalue above 1 (1.453).

The third current and preferred learning climate factor was named 'Learning Resources' and included items that related to whether training and development was left up to the individual, people were encouraged to experiment and try new things, and where work practices were constantly changing. For the current learning climate the three items explained $45.846 \%$ of the variation in the data with an Eigenvalue above 1 (1.375). For the preferred learning climate, the three items explained $43.633 \%$ of the variation in the data with an Eigenvalue above 1 (1.309).

The fourth current and preferred learning climate factor was named 'Support and Help Available' and included items that related to whether people helped each other, and whether there was a high level of social interaction amongst colleagues. For the current learning climate the three items explained $58.234 \%$ of the variation in the data with an Eigenvalue above 1 (1.747). For the preferred learning climate, the three items explained $52.104 \%$ of the variation in the data with an Eigenvalue above 1 (1.563). 
\{Table 2. Principal components analysis

for the current and preferred learning climate factors $\}$

\section{Hypothesis testing}

\section{Learning climate and affective commitment}

Correlations indicated significant relationships between current and preferred learning climate and affective commitment. Three of the four current learning climate factors were significantly positively related to affective commitment. Encouragement to Learn was significantly positively related to affective commitment $(\mathrm{r}=.558, \mathrm{p}<.05)$. Value of Ideas was significantly positively related to affective commitment $(\mathrm{r}=.447, \mathrm{p}<.05)$. Support and Help Available was significantly positively related to affective commitment $(\mathrm{r}=.395, \mathrm{p}<$ .05). Learning Resources was not significantly related to affective commitment $(\mathrm{r}=-.099, \mathrm{p}>$ $.05)$.

Two of the four preferred learning climate factors were significantly related to affective commitment. Encouragement to Learn $(r=.156, \mathrm{p}<.05)$ and Learning Resources were significantly positively related to affective commitment $(\mathrm{r}=.252, \mathrm{p}<.05)$. However, Value of Ideas $(r=-.068, p>.05)$ and Support and Help Available $(r=-.032, p>.05)$ were not significantly related to affective commitment.

\{Table 3. Summary data and bivariate correlations \}

\section{Learning climate congruence}

Significant relationships were found between two of the four current and preferred learning climate factors. A significant negative relationship was found between the current learning climate and preferred learning climate factors, Encouragement to Learn $(r=-.201, p$ 
$<.05)$ and Learning Resources $(r=-.227, p<.05)$, indicating incongruence. No significant relationships were found between Value of Ideas $(r=.062, p>.05)$ and Support and Help Available $(r=.041, p>.05)$.

\{Table 4. Mean differences and paired samples correlations for current and preferred learning climate $\}$

\section{Learning climate congruence and affective commitment}

Separate multiple regressions were used to determine how the interaction between the current and preferred organisational learning climate factors influence affective commitment. Significant interactions were found between the current and preferred learning climate factor, Encouragement to Learn, on affective commitment. For the interaction between the current and preferred learning climate factor, Encouragement to Learn $(F(3,266)=45.895, p<.05)$, the multiple correlation coefficient was $R=.586$. The relationship was significant, and $34.4 \%\left(R^{2}=.344\right)$ of the variance in affective commitment was explained by the interaction between the current and preferred learning climate factor, Encouragement to Learn $(\beta=.214$, $t=2.591, p<.05)$.

\{Table 5. Interaction effects between the current and preferred learning climate factor encouragement to learn and affective commitment\}

\{Table 6. Summary of main findings \} 


\section{Discussion}

\section{Learning climate and affective commitment}

The results partially confirmed hypothesis one and two and found significant relationships between some of the current and preferred learning climate factors and affective commitment. These findings correspond with Mikkelson, Saksvik and Ursin (1998) and Mikkelsen, Ogaard and Lovrich's (2000) research and confirmed the importance of fostering a climate that facilitates the learning.

The strongest relationships with affective commitment were found between the current learning climate factors, Encouragement to Learn, Value of Ideas and Support and Help Available and the preferred learning climate factors, Learning Resources and Encouragement to Learn. Thus, the strongest learning climate factor to predict affective commitment is Encouragement to Learn, which focuses on encouraging academics to take risk, having plenty of time to learn new tasks and openly express their ideas and opinions. Although, this indicates areas where academic managers and universities need to focus on in order to enhance the affective commitment of academics, some of these areas may be difficult due to the nature of academic work and also the bureaucratic structures that exist in many public universities (Jones 2007). However, some of these initiatives may be able to be arranged at the department level.

\section{Learning climate congruence}

The results confirmed hypothesis three and found significant relationships between current and preferred learning climate. Essentially, the person-organisation congruence theory posits that there are characteristics of an organisation that have the potential to be congruent with the characteristics of an individual (Hoffman and Woehr 2006). Thus congruence exists when individual characteristics are similar to those of the organisation. 
However, in the current study dissimilarities were found between all four of the current and preferred learning climate factors. Significant incongruence differences were discovered between two of the four factors: Encouragement to Learn and Learning Resources.

For the learning climate factor, Encouragement to Learn, the current scores were significantly lower than the preferred scores. Thus, academics appear to prefer a learning climate where employees are encouraged to take risks, have plenty of time to learn new tasks, and are encouraged to openly express their ideas and opinions (Encouragement to Learn). However, academics perceived that this situation did not necessarily exist, and that their current learning climate did not include these aspects. Thus, the results indicate that incongruence exists between the current and the preferred learning climate factor, Encouragement to Learn.

The current research, conducted on university academics found that academics needed to balance many tasks, including teaching, administration and research responsibilities. Thus, the context implies that the academics may not have enough time to learn new tasks. Further it must be noted that the current research focused on a public university, where bureaucracy appeared to be high and flexibility appeared to be low. Academics are experiencing an increasing amount of administrative responsibilities, making it even more difficult to juggle their teaching and research tasks (Siegall and McDonald 2004; Winter and Sarros 2002). The context signifies that academics may be confined to various practices and procedures and may not be encouraged to openly express their ideas and opinions.

In contrast, for the learning climate factor, Learning Resources, the current scores were significantly higher than for the preferred scores. Academics perceived the current learning climate as one where training and development was left up to the individual, with employees being encouraged to experiment and to try new things, and where work practices were constantly changing (Learning Resources). The results indicated that the learning 
climate, Learning Resources, was indicative of the university's current learning climate; however, this type of climate was the least preferred by academics. Academics appear to feel that training and development should not be left up to the individual and that the university should provide these opportunities. Although training and development opportunities may be provided by the university, they may not be suited to the individual and their needs. This may be a result of the type of organisation, as in public tertiary institutions the centralised structure and the standardisation of procedures reduces the flexibility in organisational procedures (Jones 2007), including training and development procedures. This is an important implication for academic managers and universities, where the need to recognise individual differences is critical in determining training and development needs. As a result of this, training and development may be best determined at the department level.

Academics also perceived that their university had a learning climate where employees were generally expected to conform to the rules and regulations, and where work practices and structures were constantly changing. Interestingly, the academics at this university did not perceive that they had enough time to learn or do new tasks. Time constraints and the juggling of their responsibilities of teaching and research was often an issue in such a public university.

The learning climate factors, Value of Ideas and Support and Help Available, were the most preferred. Thus, the academics preferred a learning climate where the discussion of critical work issues was valued and they were encouraged to make their own decisions (Value of Ideas), as well as a learning climate where they support each other and there is a high level of social interaction amongst their colleagues (Support and Help Available). The academics also preferred training and development resources that were practical. However, the academics least preferred a learning climate where their work practice and structures were constantly changing. Interestingly, this was perceived to be a dominant aspect of the 
university's learning climate. These findings signal important implications for academic managers and universities in order to develop the right type of training and learning in order to cater for individual needs. Also, consistency and continuity in these process and practices will further help to facilitate the type of learning climate valued by academics.

\section{Learning climate congruence and affective commitment}

The results confirmed hypothesis four and found that the congruence between current and preferred learning climate was significantly and positively related to affective commitment. Significant interactions were found between the current and preferred learning climate factor, Encouragement to Learn and affective commitment. Therefore, it is essential that an environment is created where employees are encouraged to take risks, have plenty of time to learn new tasks, and are encouraged to openly express their ideas and opinions, in order to enhance the affective commitment of their academics. Overall, the study has important implications for the development and retention of academics. Academic managers and their universities need to understand the importance of learning climate and that the congruence between individual and organisational learning climate elements is crucial to build commitment and develop better relations between their academics.

\section{Limitations}

Biases may have created limitations in the methodological procedures used in this study. First, the common method bias is a potential limitation as all the constructs used in the study were assessed through the same method, using the same respondents to determine both the dependent and independent variables. Second, sampling biases may exist as a nonprobability sampling technique was used to select participants for the research. Third, the research results are indicative of one Australian university and may not be generalisable to all 
academics and other employees working in a knowledge-intensive context. Fourth, the moderate response rate may also limit the generalisability of the results. However, this does not diminish the importance of the findings. Limitations may exist as low reliability scores were found for the current and preferred learning climate scales. Thus vigorous testing is necessary to further validate the learning climate scale.

\section{Conclusion}

The confirmed relationships between learning climate congruence and the affective commitment of university academics have important implications for the management of academics. This knowledge will enable academic managers to build commitment and develop better relations with their academics. For example whether academics are encouraged to make their own decisions, whether there is support for learning and whether training and development resources are practical. The identification of which learning elements are deemed to be of high importance, and the introduction of the right kind of learning elements, will not only improve the knowledge and skill development of academics, but also aid in the retention of these highly skilled employees.

In order to test the generalisability and robustness of the results, further research is required to examine whether the results can be applied to academics in other universities. Future research could also explore the relationships between the levels of learning climate congruence and various demographic attributes, such as gender, age, academic level and discipline and length of service. 


\section{References}

Abbott, G. N., White, F. A., and Charles, M. A. 2005. "Linking values and organizational commitment: A correlational and experimental investigation in two organizations." Journal of Occupational and Organizational Psychology 78(4): 531-551.

Allen, N. J., and Meyer, J. P. 1990. "The measurement and antecedents of affective, continuance and normative commitment to the organization." Journal of Occupational Psychology 63(1): 1-18.

Alvesson, M. 2000. "Social identify and the problem of loyalty in knowledge-intensive companies." Journal of Management Studies 37(8): 1101-1123.

Alvesson, M. 2004. Knowledge work and knowledge-intensive firms. New York, Oxford University Press.

Andrews, M. C., Baker, T., and Hunt, T. G. 2011. "Values and person-organization fit: Does moral intensity strengthen outcomes?" Leadership \& Organization Development Journal 32(1): 5-19.

Bandias, S., Fuller, D., and Pfitzner, D. 2011. "Vocational and higher education in Australia: a need for closer collaboration." Journal of Higher Education Policy and Management 33(6): 583-594.

Benson, J., and Brown, M. 2007. "Knowledge workers: What keeps them committed; what turns them away." Work, employment and society 21(1): 121-141.

Bradley, D., Noonan, P., Nugent, H., and Scales, W. 2008. Review of Australian higher Education:Final Report. Department of Education, Employment and Workplace

Relations, Canberra.

Braithwaite, J., Greenfield, D., and Westbrook, M. T. 2008. "Bifurcated variables or two sides of the same coin? Theoretical, conceptial and empirical links between 
organisational culture and climate"The Sixth International Conference on Organisational Behaviour in Health Car. City: Sydney.

Bretz, R. D., and Judge, T. A. 1994. "Person organization fit and theory of work adjustment: Implications for satisfaction, tenure and career success." Journal of Vocational Behavior 44(1): 32-54.

Cable, D. M., and DeRue, D. S. 2002. "The convergent and discriminant validity of subjective fit perceptions." Journal of Applied Psychology 87(8): 875-884.

Carless, S. A. 2005. "Person-job fit versus person-organization fit as predictors of organizational attraction and job acceptance intentions: A longitudinal study." Journal of Occupational and Organizational Psychology 78(3): 411-429.

Chan, D. 1996. "Cognitive misfit of problem solving style at work: A facet of personorganization fit." Organizational Behavior and Human Decision Processes 68(3): 194-207.

Coakes, S. J., and Steed, L. G. 2001. SPSS Analysis without anguish. Sydney, John Wiley \& Sons Australia Ltd.

Cook, P. 1996. The industrial craftsworker: Skill, managerial strategies and workplace relationships. London, Mansell.

Cunningham, P., and Iles, P. 2002. "Managing learning climates in a financial services organisation." The Journal of Management Development 21(5/6): 477-482.

Cycyota, C. S., and Harrison, D. A. 2006. "What (not) to expect when surveying executive: A meta-analysis of top manager response rates and techniques over time." Organizational Research Methods 9(2): 133-160.

Dawis, R. V., and Lofquist, L. H. 1984. A psychological theory of work adjustment. Minneapolis, University of Minnesota Press. 
Dymock, D., and McCarthy, C. 2006. "Towards a learning organization? Employee perceptions." The Learning Organization 13(5): 525-537.

Erdogan, B., and Bauer, T. N. 2005. "Enhancing career benefits of employee proactive personality: The role of fit with job and organizations." Personnel Psychology 58(4): 859-891.

Ferla, J., Valcje, M., and Cai, Y. 2009. "Academic self-efficacy and academic self-concept: Reconsidering structural relationships." Learning and Individual Differences 19: 499505.

Graham, C. M., and Nafukho, F. M. 2007. "Employees' perception toward the dimension of culture in enhancing organizational learning." The Learning Organization 14(3): 281292.

Hoffman, B. J., and Woehr, D. J. 2006. "A quantitative review of the relationship between person-organization fit and behavioral outcomes." Journal of Vocational Behavior 68(3): 389-399.

Holtom, B. C., Tidd, S. T., and Lee, T. W. 2002. "The relationship between work status congruence and work-related attitudes and behaviors." Journal of Applied Psychology 87(5): 903-915.

Horwitz, F. M., Heng, C. T., and Quazi, H. A. 2003. "Finders, keepers? Attracting, motivating and retaining knowledge workers." Human Resource Management Journal 13(4): $23-44$.

Howell, A., Kirk-Brown, A., and Cooper, B. K. 2012. "Does congruence between espoused and enacted organizational values predict affective commitment in Australian organizations?" The International Journal of Human Resource Management 23(4): 731-747. 
Iverson, R. D., and Buttigieg, D. M. 1999. "Affective, normative and continuance commitment; Can the 'right kind' of commitment be managed?" Journal of Management Studies 36(3): 307-333.

Janz, B. D., and Prasamphanich, P. 2003. "Understanding the antecedents of effective knowledge management: The importance of a knowledge-centered culture." Decision Sciences 34(2): 351-384.

Jones, G. R. 2007. Organizational theory, design and change. New Jersey, Pearson Prentice Hall.

Joo, B. 2010. "Organizational Commitment for Knowledge Workers: The Roles of Perceived Organizational Learning Culture, Leader-Member Exchange Quality, and Turnover Intention." Human Resource Development Quarterly 21(1): 69-85.

Kim, S. 2012. "Does Person-Organization Fit Matter in the Public Sector? Testing the Mediating Eff ect of Person-Organization Fit in the Relationship between Public Service Motivation and Work Attitudes." Public Administration Review, 72(6): 830840.

Kinnear, L., and Sutherland, M. 2000. "Determinants of organisational commitment amongst knowledge workers." South African Journal of Business Management 31(3): 106-112.

Kristof-Brown, A. L., Zimmerman, R. D., and Johnson, E. C. 2005. "Consequences of individuals' fit at work: A meta-analysis of person-job, person-organization, persongroup, and person-supervisor fit." Personnel Psychology 58(2): 281-342.

Kristof, A. 1996. "Person-organization fit: an integrative review of its conceptualizations, measurement and implications." Personnel Psychology 49(1): 1-49.

Lauver, K. J., and Kristof-Brown, A. 2001. "Distinguishing between employees' perceptions of person-job and person-organization fit." Journal of Vocational Behavior 59(3): 454-470. 
Lawrence, A., and Lawrence, P. 2009. "Values congruence and organisational commitment: P-O fit in higher education institutions." Journal of Academic Ethics 7: 297-314.

Lee-Kelley, L., Blackman, D. A., and Hurst, J. P. 2007. "An exploration of the relationship between learning organisations and the retention of knowledge workers." The Learning Organization 14(3): 204-221.

May, T. Y., Korczynski, M., and Frenkel, S. J. 2002. "Organizational and occupational commitment: Knowledge workers in large corporations." Journal of Management Studies 39(6): 775-801.

McDonald, D. J., and Makin, P. J. 2000. "The psychological contract, organisational commitment and job satisfaction of temporary staff." Leadership and Organization Development Journal 21(2): 84-91.

McDougall, M., and Beattie, R. S. 1998. "The missing link? Understanding the relationship between individual and organisational learning." International Journal of Training and Development 2(4): 288-299.

Meyer, J. P., and Allen, N. J. 1991. "A three-component conceptualization of organizational commitment." Human Resource Management Review 1(1): 61-89.

Meyer, J. P., and Herscovitch, L. 2001. "Commitment in the workplace: Towards a general model." Human Resource Management Review 11(3): 299-326.

Meyer, J. P., Stanley, D. J., Herscovitch, L., and Topolnytsky, L. 2002. "Affective, continuance, and normative commitment to the organization: A meta-analysis of antecedents, correlates, and consequences." Journal of Vocational Behavior 61(1): $20-52$.

Mikkelsen, A., Ogaard, T., and Lovrich, N. 2000. "Modelling the effects of organizational setting and individual coping style on employees subjective health, job satisfaction and commitment." Public Administration Quarterly 24(3): 371-397. 
Mikkelsen, A., Saksvik, P., and Ursin, H. 1998. "Job stress and organizational learning climate." International Journal of Stress Management 5(4): 197-209.

Mitchell, R., Parker, V., Giles, M., Joyce, P., and Chiang, V. 2012. "Perceived value congruence and team innovation." Journal of Occupational and Organizational Psychology 85: 626-648.

Mitchell, T. R., Holtom, B. C., and Lee, T. W. 2001. "How to keep your best employees: Developing an effective retention policy." Academy of Management Executive 15(4): 96-108.

Mohamad Najib Abdul Ghafar. 1999. "Malaysian students' skills in the sciences." Journal of Science and Mathematics Education in South East Asia 16(2): 54-59.

Morely, M. J. 2007. "Person-organization fit." Journal of Managerial Psychology 22(2): 109117.

Mowday, R. T., Porter, L. W., and Steers, R. M. 1982. Employee-organization linkages: The psychology of commitment, absenteeism, and turnover. New York, Academic Press.

Neuman, W. L. 2000. "Survey research", Social research methods: Qualitative and quantitative approaches. London: Allyn and Bacon, pp. 246-289.

O'Neill, B. S., and Adya, M. 2007. "Knowledge sharing and the psychological contract." Journal of Managerial Psychology 22(4): 411-436.

O'Reilly, C. A., Chatman, J., and Caldwell, D. F. 1991. "People and organizational culture: A profile comparison approach to assessing person-organization fit." Academy of Management Journal 34(3): 487-516.

Ortenblad, A. 2002. "A typology of the idea of learning organisation." Management Learning 33(2): 213-230.

Pedler, M., Burgoyne, J., and Boydell, T. 1991. The learning company: A strategy for sustainable development. London, McGraw-Hill. 
Piasentin, K. A., and Chapman, D. S. 2006. "Subjective person-organization fit: Bridging the gap between conceptualization and measurement." Journal of Vocational Behavior 69(2): 202-221.

Roberston, M., and Hammersley, G. 2000. "Knowledge management practices within a knowledge-intensive firm: The significance of the people management dimension." Journal of European Industrial Training 24(2/3/4): 241-253.

Senge, P. 1990. The fifth discipline. New York, Doubleday.

Shah, M., Lewis, I., and Fitzgerald, R. 2011. "The renewal of quality assurance in Australian higher education: the challenge of balancing academic rigour,equity and quality outcomes." Quality in Higher Education 17(3): 265-278.

Siegall, M., and McDonald, T. 2004. "Person-organization value congruence, burnout and diversion of resources." Personnel Review 33(3): 291-301.

Tabachnick, B. G., and Fidell, L. S. 2001. Using multivariate statistics. Boston, Allyn and Bacon.

Tepeci, M. 2001. The effect of personal values, organizational culture, and personorganization fit on individual outcomes in the restaurant industry, The Pennsylvania State University.

Thite, M. 2004. "Strategic positioning of HRM in knowledge-based organizations." The Learning Organization 11(1): 28-44.

Thomsen, H. K., and Hoest, V. 2001. "Employees' perception of the learning organization." Management Learning 32(4): 469-491.

van Balan, B., van Arensbergen, P., van der Weijden, I., and van den Besselaar, P. 2012. "Determinants of sucess in academic careers." Higher Education Policy 25: 313-334. 
Van Vuuren, M., De Jong, M. D. T., and Seydel, E. R. 2007. "Direct and indirect effects of supervisor communication on organizational commitment." Corporate Communications: An International Journal 12(2): 116-128.

VanVianen, A. E. M. 2000. "Person-organization fit: The match between newcomers' and recruiters' preferences for organizational cultures." Personnel Psychology 53(1): 113149.

Verquer, M. L., Beehr, T. A., and Wagner, S. H. 2003. "A meta-analysis of relations between person-Organization fit and work attitudes." Journal of Vocational Behavior 63(3): 473-489.

Wasti, S. A. 2003. "Organizational commitment, turnover intentions and the influence of cultural values." Journal of Occupational and Organizational Psychology 76(3): 303.

Westerman, J. W., and Cyr, L. A. 2004. "An integrative analysis of person-organization fit theories." International Journal of Selection and Assessment 12(3): 252-261.

Wheeler, A. R., Gallagher, V. C., Brouer, E. L., and Sablynskil, C. J. 2007. "When personorganization (mis)fit and (dis)satisfaction lead to turnover: The moderating role of perceived job mobility." Journal of Managerial Psychology 22(2): 203-219.

Winter, R., and Sarros, J. 2002. "The academic work environment in Australian universities: A motivating place to work?" Higher Education Research and Development 21(3): 241-258.

Wong, C. 2007. "Academic Staff Employment Statistics". City: Planning and Statistics Department, Griffith University: Gold Coast. 